Methods Total 495 SLE patients were enrolled. Among them, 162 with infection were determined by a positive pathogen test from various specimens or clear evidence of infection. Lymphocyte subpopulations were analyzed by flow cytometry in peripheral blood of these patients as well as 132 age-and sex-matched healthy donors. To investigate effects of low-dose IL-2 on these subsets in infection conditions, 54 patients with $(n=13)$ or without $(n=41)$ infection were received the treatment of IL-2 at 0.5 million IU per day for 5 days subcutaneously.

Results Notably, the absolute numbers of lymphocyte subpopulations in peripheral blood such as T, B, NK, CD4 + T, CD8 + T, Th1, Th2, Th17 and Treg cells in infected patients were the lowest among three groups $(\mathrm{p}<0.05$ to $\mathrm{p}<0.01)$, and non-infected patients had a higher level of Th17 and a lower level of Treg cells than those of healthy controls $(\mathrm{p}<0.05)$. Five days after low-dose IL-2 treatment, compared with the baselines before treatment, there was a significant increase in the number of studied lymphocyte subpopulations except NK cells: T $(\mathrm{p}<0.001), \mathrm{B} \quad(\mathrm{p}<0.001)$, CD4 +T $(\mathrm{p}<0.01), \quad$ CD8 + T $\quad(\mathrm{p}<0.001), \quad$ Th1 $\quad(\mathrm{p}<0.01), \quad$ Th17 $(\mathrm{p}<0.05)$ and Treg cells $(\mathrm{p}<0.01)$. Interestingly, low-dose IL2 markedly raised the absolute number of Tregs in SLE patients to an even higher level than that of healthy donors $(\mathrm{p}<0.001)$ and concomitantly, it moderately increased Th17 cells. In addition, part of patients received IL-2 therapy had a decrease in erythrocyte sedimentation rate $(\mathrm{ESR}, \mathrm{p}<0.001)$ and increased in blood routine measures such as platelet $(\mathrm{p}<0.05)$, WBC, lymphocyte and neutrophil $(\mathrm{p}<0.005)$ after the treatment.
Conclusions Patients with SLE, especially those suffering infections, had a disturbance in immune system by decreased number of various lymphocyte subsets. This preliminary finding suggests that low-dose IL-2 combination treatments restored the decreased number of lymphocyte subpopulations, neutrophils and platelets and lowered ESR of these patients. Further studies are needed to evaluate the long-term anti-infection ability of IL-2 treatment.

Funding Source(s): None

\section{CLUSTER ANALYSIS OF PATIENTS WITH SLE IN THE ADELPHI LUPUS DISEASE SPECIFIC PROGRAMME}

${ }^{1}$ Kerry Gairy*, ${ }^{2}$ Ben Hoskin, ${ }^{2}$ David Bell, ${ }^{2}$ Olivia Massey, Justyna Amelio, ${ }^{4}$ Alex Liakos. ${ }^{1}$ GlaxoSmithKline, Value Evidence and Outcomes, Brentford, Middlesex, UK; ${ }^{2}$ Adelphi Group, Adelphi Real World; ${ }^{3}$ GlaxoSmithKline, Real World Evidence and Epidemiology, Stevenage, Herts, UK; ${ }^{4} G S K$, Immuno-inflammation and Future Pipeline

\subsection{6/lupus-2019-Ism.49}

Background Organ system involvement in systemic lupus erythematosus (SLE) is highly variable. Better understanding of the symptom and organ involvement patterns in patients with SLE may facilitate making more accurate prognoses and individualized management decisions. This analysis aimed to categorize patients with SLE into clusters according to their organ system involvement.

Methods This was a secondary, descriptive analysis (208683) that utilized survey data collected from adult patients with SLE and their physicians, enrolled in the 2015 Adelphi Real

Abstract 49 Table 1 Clinical characteristics of SLE clusters

\begin{tabular}{|c|c|c|c|c|c|}
\hline & $\begin{array}{c}\text { Cluster 1: } \\
\text { Low burden } \\
n=250\end{array}$ & $\begin{array}{l}\text { Cluster 2: } \\
\text { 'Joint and skin' } \\
n=670\end{array}$ & $\begin{array}{l}\text { Cluster 3: } \\
\text { High burden; renal/hematologic involvement } \\
n=150\end{array}$ & $\begin{array}{l}\text { Cluster 4: } \\
\text { High burden; no renal involvement } \\
n=306\end{array}$ & $p$ value \\
\hline \multicolumn{6}{|c|}{ Organ systems currently affected, $\mathrm{n}(\%)$} \\
\hline$n$ & 250 & 670 & 150 & 306 & \\
\hline Musculoskeletal & 0 & $659(98.4)$ & $126(84.0)$ & $306(100.0)$ & $<0.0001$ \\
\hline Mucocutaneous & $72(28.8)$ & $344(51.3)$ & $64(42.7)$ & $306(100.0)$ & $<0.0001$ \\
\hline Constitutional & $14(5.6)$ & $102(15.2)$ & $82(54.7)$ & $216(70.6)$ & $<0.0001$ \\
\hline Hematologic & $42(16.8)$ & 0 & $149(99.3)$ & $186(60.8)$ & $<0.0001$ \\
\hline Renal & $34(13.6)$ & $117(17.5)$ & $87(58.0)$ & 0 & $<0.0001$ \\
\hline Cardiorespiratory & $19(7.6)$ & $39(5.8)$ & $19(12.7)$ & $46(15.0)$ & $<0.0001$ \\
\hline Neuropsychiatric & $13(5.2)$ & $33(4.9)$ & $11(7.3)$ & $32(10.5)$ & $<0.01$ \\
\hline Gastrointestinal & $3(1.2)$ & $20(3.0)$ & $12(8.0)$ & $15(4.9)$ & $<0.01$ \\
\hline Ophthalmic & $3(1.2)$ & $19(2.8)$ & $6(4.0)$ & $21(6.9)$ & $<0.01$ \\
\hline None & $74(29.6)$ & 0 & 0 & 0 & $<0.0001$ \\
\hline \multicolumn{6}{|c|}{$\begin{array}{l}\text { Number of organ systems affected, } \\
\text { mean (SD) }\end{array}$} \\
\hline $\mathrm{n}$ & 250 & 670 & 150 & 306 & \\
\hline At diagnosis & $2.3(1.3)$ & $2.1(1.1)$ & $3.6(1.4)$ & $3.4(1.1)$ & $<0.0001$ \\
\hline Currently & $0.8(0.8)$ & $2(0.9)$ & $3.7(1.3)$ & $3.7(1.3)$ & $<0.0001$ \\
\hline \multicolumn{6}{|l|}{ Time since diagnosis (weeks) } \\
\hline$n$ & 245 & 655 & 149 & 302 & \\
\hline Mean (SD) & $307.6(334.3)$ & $256.6(307.0)$ & $348.4(351.5)$ & $300.8(308.8)$ & $<0.001$ \\
\hline Current disease severity, $\mathbf{n}(\%)$ & & & & & $<0.0001$ \\
\hline$n$ & 248 & 665 & 149 & 304 & \\
\hline Mild & $218(87.9)$ & $480(72.2)$ & $93(62.4)$ & $194(63.8)$ & \\
\hline Moderate & $27(10.9)$ & $160(24.1)$ & $46(30.9)$ & $102(33.6)$ & \\
\hline Severe & $3(1.2)$ & $25(3.8)$ & $10(6.7)$ & $8(2.6)$ & \\
\hline
\end{tabular}

SD, standard deviation 
World Disease Specific Programme (US and Europe) (205086). Latent class modeling based on current organ involvement was used to generate clusters of patients with similar manifestations; characteristics of each cluster were compared using the chi-square test for categorical variables and Kruskal-Wallis test for ordered/numeric outcomes.

Results Overall, 1376 patients $(n=1196$ [87.0\%] female; mean [standard deviation (SD)] ) age, 42.1 [13.6] years) were included in the analysis. Four patient clusters were generated: Cluster $1(\mathrm{n}=250,18.2 \%)$, lowest overall organ burden (predominantly mucocutaneous); Cluster $2(n=670,48.7 \%)$, joint and skin SLE (predominantly mucocutaneous and musculoskeletal) with limited renal/hematologic involvement; Cluster 3 $(\mathrm{n}=150,10.9 \%)$, highest frequency of renal/hematologic involvement; Cluster $4(\mathrm{n}=306,22.2 \%)$, highest frequency of mucocutaneous, musculoskeletal, constitutional, cardiorespiratory and neuropsychiatric involvement, but without renal involvement. Key results are summarized in the table 1. Significant between-cluster differences were observed for disease severity $(p<0.0001$; highest: Cluster 3$)$; number of affected organ systems $(p<0.0001$; highest: Clusters 3 and 4$)$; number of flares in prior 12 months $(p<0.0001$; highest: Clusters 3 and 4); disease progression $(\mathrm{p}<0.0001$; most compromised: Cluster 3$)$; time since diagnosis $(\mathrm{p}<0.001$; longest: Cluster 3$)$; and ethnicity $(\mathrm{p}<0.01$; black race most prevalent: Cluster 3). Overall, the most commonly experienced symptoms were pain/inflammation and skin symptoms $(p<0.0001$; highest: Cluster 4$)$. Frequency of organ involvement increased over time in Clusters 3 and 4 but decreased in Cluster 1. Statistically significant differences were observed between clusters in the number of previous treatments and treatment classes (both $\mathrm{p}<0.01$ ). Activity impairment generally increased, while fatigue severity worsened, across the clusters (both <0.0001).

Conclusions This analysis provides important insights on potential clinically meaningful subsets of SLE (per organ system involvement) using real-world evidence. The highest disease burden was observed in Clusters 3 and 4, confirming the extensive impact of SLE irrespective of renal involvement. Limitations included the absence of serological findings or disease activity indices for cluster formation or comparison.

Funding Source(s): Study funded by GlaxoSmithKline; ownership of data retained by Adelphi Real World.

\section{PATIENT INSIGHTS OF FATIGUE IN SYSTEMIC LUPUS ERYTHEMATOSUS AND CONTENT VALIDATION OF THE FACIT-FATIGUE}

${ }^{1}$ Josephine Park*, ${ }^{2}$ Kimberly Raymond, ${ }^{2}$ Michelle White, ${ }^{1}$ Ashish Joshi. ${ }^{1}$ GSK, Value Evidence and Outcomes; ${ }^{2}$ Optum

\subsection{6/lupus-2019-Ism.50}

Background Fatigue is a predominant symptom experienced by patients with systemic lupus erythematosus (SLE) and is known to have a significant burden on daily life. To capture the impact of fatigue on patients with SLE accurately and effectively, a validated fatigue measure must be utilized. This study (GSK Study 209226) evaluated the content validity of the Functional Assessment of Chronic Illness Therapy (FACIT) Fatigue instrument to investigate whether this instrument is a valid and appropriate measure of fatigue
Abstract 50 Table 1 Concepts discussed within the CE segment of the interview

\begin{tabular}{|c|c|}
\hline Concepts relating to SLE, $\mathrm{n}(\%)^{*}$ & $\begin{array}{l}\text { Patients } \\
(n=15)\end{array}$ \\
\hline \multicolumn{2}{|l|}{ Impact of fatigue on reported functions } \\
\hline Emotional Functioning & $10(66.7)$ \\
\hline Physical Functioning & $5(33.3)$ \\
\hline Social Functioning & $6(40.0)$ \\
\hline Activities of Daily Living & $4(26.7)$ \\
\hline Role Functioning & $4(26.7)$ \\
\hline \multicolumn{2}{|l|}{ Most commonly reported symptoms } \\
\hline Cognitive functioning & $15(100.0)$ \\
\hline Fatigue & $15(100.0)$ \\
\hline Pain & $15(100.0)$ \\
\hline Sleep disturbance & $15(100.0)$ \\
\hline Weakness & $12(80.0)$ \\
\hline Nervous, brain & $9(60.0)$ \\
\hline Skin & $9(60.0)$ \\
\hline Arthritis & $6(40.0)$ \\
\hline Hair loss & $5(33.3)$ \\
\hline Kidney & $5(33.3)$ \\
\hline Light-headedness & $5(33.3)$ \\
\hline Swelling & $5(33.3)$ \\
\hline Ulcers & $5(33.3)$ \\
\hline Vascular & $5(33.3)$ \\
\hline $\begin{array}{l}\text { Number of patients with symptoms reported to vary in intensity } \\
\text { over time }\end{array}$ & $9(60.0)$ \\
\hline Triggers reported to intensify symptoms (any) & $14(93.3)$ \\
\hline Exposure to sun/photosensitivity & $12(80.0)$ \\
\hline Physical exertion & $10(66.7)$ \\
\hline Stress & $5(33.3)$ \\
\hline Cold weather & $3(20.0)$ \\
\hline Diet & $2(13.3)$ \\
\hline Stopping medication & $2(13.3)$ \\
\hline \multicolumn{2}{|l|}{ Symptoms reported as the most bothersome } \\
\hline Fatigue & $11(73.3)$ \\
\hline Pain & $3(20.0)$ \\
\hline Difficulty concentrating & $1(6.7)$ \\
\hline Hair loss & $1(6.7)$ \\
\hline Insomnia & $1(6.7)$ \\
\hline Lupus nephritis/inflammation of the kidney & $1(6.7)$ \\
\hline Raynaud's phenomenon & $1(6.7)$ \\
\hline
\end{tabular}

CE, concept elicitation; SLE, systemic lupus erythematosus. *Percentages in each category may not total $100 \%$ because participants may have reported more than one symptom, trigger, or impact.

within this population and to understand SLE related fatigue better.

Methods Fifteen $90 \mathrm{~min}$ qualitative interviews were conducted by telephone in July 2018 using concept elicitation (CE) and cognitive debriefing techniques. Participants were asked to share their experiences of SLE symptoms, focusing on fatigue and its impact on their daily life. Participants were then asked to evaluate how well they interpreted and understood the questions and response options of the FACIT-Fatigue instrument, along with the appropriateness and relevance of the items, response scales and recall periods. Patients were eligible to participate if they were 18 years of age, had a self reported doctor diagnosis of SLE with persistent symptoms for 6 months or 1 SLE flare in the previous 12 months despite treatment with steroids/ 